\title{
Innovative Methods in Medical Education in Bulgaria: Video Materials and Serious Games
}

\author{
https://doi.org/10.3991/ijet.v14i16.10607 \\ Galya Georgieva-Tsaneva \\ Bulgarian Academy of Sciences, Sofia, Bulgaria \\ galicaneva@abv.bg
}

\begin{abstract}
Modern trends in teaching and learning aim to use effective methods by which students better understand the learning material and are more involved in the learning process. These methods should take into account the ability of today's students to work multifunctional and quickly process large amounts of information. The introduction of modern technology in the classroom is the most important change in education now. This article examines ways to provide specialized medical information in an intriguing interactive way, geared towards effective support for medical students. The paper presents new methods included in the training of medical students in Bulgaria: Video algorithms that show didactically in detail the necessary sequence of actions to perform a particular medical manipulation, including everything they need to know and can make the student achieve this skill. In order to better master the series of actions involved in the manipulation and the acquisition of preliminary experience, it is proposed to include Simulation Games in the medical training. The use of Serious Simulation Games in medical training helps to improve the skills of future medics and to build self-confident specialists.
\end{abstract}

Keywords - Higher education, Serious Games, medicine, simulation, video materials.

\section{Introduction}

Modern information technologies enable the use of interactive methods in the twoway teaching-learning process and are a means of using non-standard learning methods that are able to mobilize the capabilities of students, to concentrate them and to derive their maximum capacity to learn, understand and apply the learning [15]. Active participation during training is a good means for obtaining lasting knowledge. Teachers today need to use a variety of tools to raise the level of the educational process: presentations of the course material, coursework, videos, Serious Educational Games, practical exercises, etc. This paper focuses on the specificities of medical education in Bulgaria and aims to offer innovative strategies for improving the learning process in higher education universities on medicine in the country, by including video algorithms and Simulation Training Games. The new generation, born and raised in the era of ubiquitous technology penetration in everyday activities of 
man, challenges teachers to enrich, change, improve their pedagogical methods, opening the door of the classroom to new technologies. Today's students spend hours with video games, so lessons and training with video games will cause interest and would bring positive educational outcomes. Educational Games in the form of simulations can be very useful in working out new actions, creating new skills and creating a sense of confidence in learners. They are an innovative tool for building skills by simulating more complex actions and repeating them repeatedly until success obtaining. Presentations and video materials can be used as a means of concentrating material and enriching with new knowledge.

\section{Features and Problems of Education Today}

The teacher has to adjust, adapt teaching methods to the way students perceive. The modern generation teaches visually and wants to learn things that can be implemented immediately. This generation has a potential the teacher has to reach and reveal. This requires the educational system to adapt to the new model of students who have a rich visual experience, live in an interactive, interesting, multi-layered technological environment. The classic way of information presenting is no longer a solution. Therefore, the teacher has to get them to act by making presentations, studying a problem, teaching a lesson, and so on. Video tutorials, role-playing games, and Serious Computer Games should be introduced to the lessons. Video games have varying levels of complexity, and a different scenario in each level, a different story is told, a different environment emerges, according to which the user adjusts his actions.

Main disadvantages of traditional training:

- Passive learning, students are not actively involved in the learning process

- The theory and practice are artificially separated

- Trainees find themselves surrounded by uninteresting terms, theories, concepts that must reproduce

- A very small percentage of the material taught by traditional methods is remembered

\section{Creating Serious Educational Games and Using them for the Purposes of Medical Education}

The first educational computer game "The Oregon Trail" was developed in 1971 like education software for the classroom от Minnesota Educational Computing Consortium to some schools in Minnesota. The serious game was made available on the Apple II platform to all people in 1985. The game became one of the most popular computer programs, with thousands of players monthly [3].

In 1987, Clark C. Abt in his book "Serious Games" [1] introduces this term: "game having explicit and carefully crystallized educational purposes, as the main goal is not entertainment". 
Nowadays, Serious Educational Games are used for learning purposes in various schools' disciplines: languages, mathematics, natural sciences, medical sciences, etc. The authors of the [4] study over 30 papers on mathematics games; they view games as a tool to help students understand the fundamental concepts of mathematics, developing critical thinking and motivation method for their development in this discipline.

In the field of medicine, one of the first Serious Games to play is Pusle!, it offers quality graphics in human anatomy reproduction and people's actions, and has a good design. The game allows for the training of the medical professionals in the presence of bioterrorism and bombardments.

In their study [6], the authors find that Serious Medical Games are oriented primarily towards educational purposes and for increasing medical skills.

Lelardeux and all [8] create and explore play scenarios (with an educational purpose) for acting in a standard medical situation and when a non-standard situation occurs. As a result, they create a methodology for creating a risk management scenario that has an educational focus. In health care, it should be taken into account the thesis that, in addition to the illness, and the medical team can harm the patient. The equipment used and even the hospital itself can harm, so adequate steps must be taken to prevent such events.

Sabri and all [10] present a Serious Training Game for the purposes of cardiac surgery. Performing some cardiac operations are very complex and require significant skills that cannot be learned in a real patient operation due to a serious risk of harm to the patient. The authors have developed an interactive, training multi-player game to simulate off-pump coronary artery bypass grafting (coronary artery is blocked and bypassed with a healthy artery or vein). The game uses 3D graphics API, 3D modeling and visual effects software (using the graphics processing unit), the created models are extremely realistic.

In the past years in modern learning uses training through Simulation Games. The shortest definition for the simulation is given by Prensky in the book "Digital GameBased Learning": the simulation is a representation; every simulation is created on a particular model [9]. The first created Simulation Game is Top Management Decision Simulation (1956) [7]. Aldrich [2] describes the simulation as model-based and the role of someone in it, describing the possible actions that can be taken, the impact of these actions on the environment, and receiving feedback after changing the virtual environment by showing results of the actions taken.

Simulation Games are an appropriate tool for creating new skills and reinforcing newly acquired skills in different areas of life: for pilot training is appropriate to simulate flying and landing of a plane; when driving a car: turning in sharp turns, driving at high speed, etc. According to [5], Simulation Games not only enable real-life situations to be reproduced, but they also help to apply the lessons learned in situations close to the real ones. 


\section{Modern Technologies in Medical Education in Bulgaria}

For medical and healthcare professionals, it is necessary to successfully master a multitude of interdisciplinary knowledge, excellent skills, and opportunities for patient care. Students should form professional knowledge and skills and be able to apply them confidently in every real situation with a particular individual. In order not to endanger the health of this individual, it is necessary to avoid making any mistakes, so it is necessary to obtain prior experience.

In this paper, the following approach is proposed for medical education: combining video presentations, simulations, and Serious Educational Games as a means to improve the learning outcomes in a theoretical and practical aspect. The following must be observed when creating visual materials, Simulation Games, and Serious Games: a unified methodology for developing individual components; onto-didactic selection of the content and structural composition of the didactic component [12].

Combined with problem-based learning, Serious Educational Games in the medical field contribute to:

- Increasing the competence of the students in the field studied

- Increasing the attention and activity of the students

- Increasing the students' interest in the material studied

- Accumulation of experience in an environment close to the real

- Creating future self-confident medics

Two of the specialties related to the provision of health care for the population is the specialties Midwife and Medical nurse. In these specialties, students have to master multiple procedures, one of which is giving an injection to a patient. The non-good injection technique carries a high risk for the patient. When mastering the profession, it is necessary for the student to be able to perform several manipulations independently, including subcutaneous, intravenous and intramuscular injections. In addition to listening to a lecture course, the practical exercises are conducted under the supervision of the lecturer and manipulations are performed on an artificial model of a human body. The student must acquire knowledge and develop the necessary skills to make an injection without error. Major issues faced by students: uncertainty and even fear and stress of whether they will be able to cope with manipulations well enough: making mistakes is not an option.

Approaches used in the course: lecture course, multimedia presentations, interactive methods, practical exercises, videos, discussions of unclear elements of the studied manipulation. The video is a very appropriate method by which the sequence of certain actions can be captured for the purpose of properly conducting medical manipulation. Filmed under the guidance of an experienced pedagogue, video materials can be a valuable assistant in student education.

Additionally, after conducting the lecture course and following the seeing of the video algorithm for the relevant manipulation, a good continuation for the learning of the injection technique will be the inclusion of virtual simulation in the training process by using a dedicated virtual simulation software developed for this purpose. 
This will allow repeated repetition of all elements of the staged manipulation; which elements are repeated until the necessary perfection in sequence and accuracy of the actions is achieved. The simulation algorithm is designed so that each part of the manipulation to be performed is repeated until the learner is actually fully prepared. The use of such simulations will increase the confidence of the prospective medic, will give a preliminary experience and will be a good guarantee for the successful practice of manipulation.

Serious Educational Games can use the dynamics the games offer in a simulated part of real life. The use of serious games in medical education to master the ability to apply injection technique may put the student in a position to solve independently (in keeping with what has been learned in the learning process) the following questions: where exactly to put the injection in which part of the human body, in which more precise area; how to put the injection, at what angle, and more. At the same time, video games have the ability to change some of the circumstances of virtual reality and to recreate different virtual conditions of the event each time, which will give the student a very valuable experience of reacting under changing circumstances.

\section{Results of the Study on the Use of Innovative Technologies in Medical Education in Bulgaria}

Medical students in Bulgaria apply the lessons learned about injecting techniques by training with artificial models of the human body. However, the students do not feel confident enough about their ability and in the success of doing the given manipulation in real conditions. According to the analysis of a survey conducted at the Faculty of Public Health of Angel Kanchev University of Rousse, Bulgaria: 63\% of respondents express their opinion that they want to be given additional possibilities for absorption of the injection technique [13].

The series of educational video algorithms for injection technique [13] was developed by Angel Kanchev University, Rousse, Department of Health Care, Bulgaria under a project to the Bulgarian Research Fund. Video algorithms are detailed, the actions performed are exhaustive and clearly explained and the interest to them is great. So the video algorithm "Subcutaneous injection" of 16 May 2015 (when uploaded to YouTube) until 05.04.2019 has over 38510 views. This for about 4 years is over 9600 times per year and over 26 times a day. These statistics data show the real relevance of the video algorithm and the need for students to use similar videos.

Done research shows that Video Algorithms have been successfully used in teaching the relevant material in the training of the Nurse and Midwave specialty at the Medical Universities in Bulgaria.

Advantages of video algorithms: Can be viewed many times; can pause and repeat a certain part many times; can be run from certain locations, can be viewed before manipulation, before the exam, and so on.

Advantages of the use of Serious Simulation Games: Each element can be trained many times through a simulation in and the game does not let the user move if he did not achieve a certain degree of accuracy of performance; students acquire ex- 
perience in an environment close to the real without causing patient pain and under conditions that are comfortable for the students. As a result of the many experiments made, in a real-life environment, the students gain confidence in their own abilities and raise both their skills and their self-esteem.

\section{Conclusion}

The use of innovative technologies in Bulgaria makes its first steps. The process of applying methods such as video materials, Simulation Games, presentations has begun in the Medical Universities of the country. The developed video algorithms of the University of Rousse are applied by lecturers in the respective medical specialty at several Medical Universities in the country and are welcomed by the students with interest and have been repeatedly used, as can be assured by the statistics data on the Internet. The use of presentations and video materials in the educational process is a prerequisite for acquiring lasting, excellent knowledge in the relevant medical specialty. The implementation of Simulation Games in order to acquire skills in conditions close to the real, safe environment will be able to meet the aspirations of the new generation for innovative educational means and will contribute to the development of capable, well-mastered medical manipulations and confident medical specialists. The study shows that learning in the field of medicine is more successful with the implementation of new information technology tools and modern educational approaches embedded in Serious Games and video algorithms for learning purposes.

\section{$7 \quad$ Acknowledgement}

This work was supported by the Bulgarian Ministry of Education and Science under the National Research Program "Young scientists and postdoctoral students" approved by DCM \# 577 / 17.08.2018.

\section{$8 \quad$ References}

[1] Abt, C. (1987). Serious games. University Press of America.

[2] Aldrich, C. (2009). Learning online with games, simulations and virtual worlds,

[3] Bouchard, R. (2017). How I Managed to Design the Most Successful Educational Computer Game of All Time. Medium. https://medium.com/the-philipendium/how-i-managedto-design-the-most-successful-educational-computer-game-of-all-time-4626ea09e 184

[4] Drigas A, Pappas A. (2015). Online and other Game-based Learning for Mathematics, International Journal of Online Engineering, 11(4): 62-67

[5] Faizan N., Löffler A., Heininger R. (2019). Classification of Evaluation Methods for the Effective Assessment of Simulation Games: Results from a Literature Review. International Journal of Engineering Pedagogy, 9(1): 19-33.https://doi.org/10.3991/ijep.v9i1.9948

[6] Graafland M., Schraagen J., Schijven M. (2012). A systematic review of serious games for medical education and surgical skills training, British Journal of Surgery, 99: 1322-1330 https://doi.org/10.1002/bjs.8819 
[7] Hodgetts R. (1970). Management gaming for didactic purposes: A new look. Simulation and Games, 1 (1): 55-66. https://doi.org/10.1177/104687817000100105

[8] Lelardeux C. P., Galaup M., Panzoli D., Lagarrigue P., Jessel J-P. (2018). A Method to Design a Multi-Player Educational Scenario to Make Interdisciplinary Teams Experiment Risk Management Situation in a Digital Collaborative Learning Game: A Case of Study in Healthcare. International Journal of Engineering Pedagogy, 8 (2): 88-100 https://doi.org/ 10.3991/ijep.v8i2.8140

[9] Prensky M. (2000). Digital Game-Based Learning. (on-line) http://www.marcprensky.com/ writing/Prensky\%20-\%20Ch2-Digital\%20Game-Based\%20Learning.pdf

[10] Sabri H, Cowan B, Kapralos B, Moussa F, Cristancho S, Dubrows A. (2011). A serious game for Off-Pump Coronary Artery Bypass Surgery Procedure Training Meets Serious Games. Studies in health technology and informatics. 163:147-9 https://doi.org/10.1109/ have.2010.5623995

[11] Sebastian L.C., Sheng Y., Ifenthaler D., (Editors). (2015). Serious Games Analytics. Methodologies for Performance Measurement, Assessment, and Improvement. Advances in Game-Based Learning. Springer. International Publishing Switzerland. https://doi.org/ 10.1007/978-3-319-05834-4

[12] Serbezova I., Optimize training in health care through video methods. (2018). MediatechPleven (in Bulgarian)

[13] Serbezova I., Video films in the training of medical and healthcare professionals. (2013). Rousse University "Angel Kanchev"(in Bulgarian)

[14] Serbezova I., Velcheva K., Lukanova Y. (2015). Midwive Students and the Need to Optimize the Training in Injection Techniques, Scientific Works of the University of Rousse, 54 (8.3): 45-49. http://conf.uni-ruse.bg/bg/docs/cp15/8.3/8.3-7.pdf (in Bulgarian)

[15] Tramonti M., Paneva-Marinova D. (2019). Maths, Art, and Technology: a Combination for an Effective Study. TEM Journal. 8 (1): 82-86.

\section{$9 \quad$ Author}

Galya Georgieva-Tsaneva, Ph.D. is an Assistant Professor at the Institute of Robotics, Bulgarian Academy of Sciences, Sofia, Bulgaria. Her scientific research interests include serious educational games, web accessibility, medical information system, investigation of Heart Rate Variability of ECG data, wavelet and fractal analysis, coding and compression of information, fractal modeling, computer networks and communications, tele traffic engineering.

Article submitted 2019-03-05. Resubmitted 2019-04-05. Final acceptance 2019-06-08. Final version published as submitted by the authors 